\title{
Adaptabilidade e danos potenciais de Rhizoctonia oryzae-sativae ao milho
}

\author{
Samara Nunes Campos Vicentini ${ }^{1}$, Danilo Augusto Pereira dos Santos ${ }^{1,2}$, Vanina Lilián Castroagudín ${ }^{1}$, Adriano \\ Francis Dorigan ${ }^{1}$, Paulo Cezar Ceresini ${ }^{1}$.
}

\begin{abstract}
${ }^{1}$ Universidade Estadual Paulista (UNESP), Campus de Ilha Solteira, Departamento de Fitossanidade, Engenharia Rural e Solos, Ilha Solteira, São Paulo, Brasil. ${ }^{2}$ Swiss Federal Institute of Technology (ETH Zurich), Plant Pathology Group, Zurich, Switzerland.

Autor para correspondência: Paulo Cezar Ceresini (paulo.ceresini@bio.feis.unesp.br)

Data de chegada: 16/06/2016. Aceito para publicação em: 13/03/2017.
\end{abstract}

$10.1590 / 0100-5405 / 2205$

\section{RESUMO}

Vicentini, S.N.C.; Santos, D.A.P.; Castroagudín, V.L.; Dorigan, A.F.; Ceresini, P.C. Adaptabilidade e danos potenciais de Rhizoctonia oryzaesativae ao milho. Summa Phytopathologica, v.43, n.3, p.186-192, 2017.

Espécies do gênero Rhizoctonia estão associadas ao complexo de manchas da bainha do arroz, sendo que $R$. oryzae-sativae, em particular, causa a mancha agregada da bainha. Neste estudo objetivou-se determinar o potencial adaptativo de duas populações de Rhizoctonia oryzae-sativae à cultura do milho, uma das culturas comerciais amplamente cultivadas no estado de São Paulo e que pode ser utilizada em rotação com o arroz irrigado. Não há relatos da doença em milho no Brasil. Foram inoculados, em plantas de milho, isolados de duas populações de $R$. oryzae-sativae e determinou-se componentes de evolucionabilidade ou do potencial adaptativo de uma população (i.e., medidas de resposta à seleção) como os coeficientes de variância genotípica $\left(I_{G}\right)$, variância ambiental $\left(I_{E}\right)$ e a herdabilidade $\left(h^{2}\right)$ para os níveis de agressividade da doença. Comparouse também a diferenciação fenotípica por caracteres quantitativos $\left(Q_{S T}\right)$ e a diferenciação genética neutra (baseada em dados de microssatélites) nas duas populações $\left(F_{S T}\right)$. Experimentos similares usando plantas de arroz inoculadas com as duas populações do patógeno foram conduzidos como controle. Os isolados das populações de $R$. oryzae-sativae foram patogênicos e apresentaram variação na agressividade ao milho, com predominância de baixa herdabilidade para este atributo. Os valores estimados de $Q_{S T}$ não diferiram significativamente de $F_{S T}$ indicando que a neutralidade teve importante papel na adaptação regional de populações do patógeno.

Palavras-chave:Potencial adaptativo, agressividade, $Q_{S T}, F_{S T}$, componentes de evolucionabilidade.

\section{ABSTRACT}

Vicentini, S.N.C.; Santos, D.A.P.; Castroagudín, V.L.; Dorigan, A.F.; Ceresini, P.C. Adaptability and damage of Rhizoctonia oryzae-sativae to maize. Summa Phytopathologica, v.43, n.3, p.186-192, 2017.

Rhizoctonia species are associated with rice sheath-blight complex, and $R$. oryzae-sativae, in particular, causes aggregate sheath spot. This study aimed to determine the adaptive potential of two populations of R. oryzae-sativae to maize, one of the cash crops widely grown in São Paulo State and that could be used in rotation with irrigated rice. There is no report of the disease on maize in Brazil. Isolates of two populations of R. oryzae-sativae were inoculated in maize plants and components of evolvability or adaptive potential of a population (i.e., estimates of response to selection) were determined, such as genotypic variance coefficients $\left(I_{G}\right)$, environmental variance $\left(I_{E}\right)$ and heritability $\left(h^{2}\right)$ for the disease aggressiveness levels. Phenotypic differentiation based on quantitative traits $\left(Q_{S T}\right)$ was also compared with neutral genetic differentiation (based on microsatellite data) in the two populations $\left(F_{S T}\right)$. Similar experiments using rice plants inoculated with the two populations of the pathogen were used as controls. Isolates from $R$. oryzae-sativae populations were pathogenic and had varied aggressiveness in maize, and low heritalibity predominated for this trait. The estimated values of $Q_{S T}$ did not differ significantly from those of $F_{S T}$, indicating that neutrality played an important role in the regional adaptation of the pathogen populations.

Keywords: Adaptive potential, aggressiveness, $Q_{S T}, F_{S T}$, evolvability components.

O complexo de doenças das manchas e queimas da bainha do arroz está associado a fungos do gênero Rhizoctonia, sendo o fungo $R$. oryzae-sativae o agente causal da mancha agregada da bainha e o fungo $R$. solani AG-1 IA o patógeno da queima da bainha (1). Esse complexo de doenças vem se tornando importante nas regiões de cultivo de arroz, como na Califórnia e sudeste da Austrália, pois as perdas de rendimentos ocasionadas pela doença demonstraram uma potencial ameaça para as indústrias de processamento de arroz (17). No Brasil, os fungos $R$. oryzae-sativae e $R$. solani AG-1 IA foram relatados pela primeira vez como agentes causais das doenças da bainha em lavouras de arroz no interior do estado de São Paulo em 1967 e, em seguida, no Rio Grande do Sul em $1970(1 ; 19)$. Além de fitopatógenos bastante destrutivos, fungos do gênero Rhizoctonia são organismos necrotróficos habitantes do solo, podendo sobreviver nas áreas de cultivo de arroz em restos de cultura e na forma de estruturas de resistência do tipo escleródios (30).

Informação sobre a ocorrência e distribuição e importância relativa das espécies de Rhizoctonia que estão associadas ao complexo de manchas e queimas da bainha em arroz são de extrema relevância para o manejo da doença, que depende basicamente, da adoção de resistência varietal e do controle químico (19). Inerente a este fato, em estudos realizados na região do Vale do Paraíba, SP, detectou-se a prevalência de $R$. oryzae-sativae associado ao complexo de manchas da bainha do arroz, em 2013 (20).

Desde o século XIX a região do Vale do Paraíba apresenta importância econômica na exploração agrícola, destacando-se na produção de alimentos, em especial arroz, feijão e milho (9). Devido ao uso intensivo das áreas agrícolas nessa região, preconiza-se a implementação de práticas conservacionistas do solo e de manejo 
cultural de doenças, dentre estas, a rotação de culturas vem sendo amplamente utilizada (25).

Conceitualmente, a seleção de espécies para rotação deve basear-se na diversidade botânica com plantas de diferentes sistemas radiculares, hábitos de crescimento e exigências nutricionais (23). Adicionalmente, evitar o cultivo de plantas de mesma família botânica em uma mesma área e em sequência temporal é um critério ecológico importante, pois muitas pragas e doenças atacam culturas de mesma família (4). Entretanto, dentre as opções de espécies para o uso em rotação com o arroz irrigado recomenda-se a cultura do milho (12), mesmo sendo ambos pertencentes à família Poaceae.

Embora frequentemente recomendado por razões econômicas, sob o ponto de vista fitossanitário é importante evitar o cultivo em uma mesma área de culturas que pertençam à mesma família botânica a fim de impedir que se selecione fitopatógenos que passem a atacar diversos hospedeiros dessa mesma família (26). A exemplo disso, o patógeno $R$. solani AG1-IA é relatado causando a queima da bainha no arroz, a mancha bandeada no milho, e a queima foliar de braquiária (Urochloa ssp.), todas culturas importantes da família Poaceae $(3 ; 13)$.

Em estudo recente desenvolvido com populações de $R$. oryzaesativae do Vale do Paraíba, SP, observou-se que isolados que infectam arroz apresentam patogenicidade e variação fenotípica e genética para agressividade ao capim braquiária podendo ter sua gama de hospedeiros expandida para infectar este hospedeiro (20). Por conseguinte, sob condições de alta pressão de seleção imposta pela rotação de cultura com milho, populações de $R$. oryzae-sativae do arroz poderiam se adaptar ao milho, à semelhança do observado para $R$. solani AG-1 IA do arroz na Venezuela, que emergiu como importante patógeno do milho $(3 ; 13)$. Nesse contexto, o objetivo deste trabalho foi determinar se populações de $R$. oryzae-sativae do agroecossistema do Vale do Paraíba possuem potencial de adaptar-se e emergir como patógeno na cultura do milho.

\section{MATERIAL E MÉTODOS}

\section{Amostras de populações de $\boldsymbol{R}$. oryzae-sativae.}

Os isolados utilizados neste estudo foram obtidos por amostragem de populações de $R$. oryzae-sativae, agente causal da mancha agregada da bainha, em áreas de cultivo comercial de arroz na região do Vale do Paraíba, SP, nos municípios de Guaratinguetá, Pindamonhangaba, Roseira, Taubaté e Tremembé, em 2013. Foi usado o sistema de amostragem por transectos lineares compostos por seis linhas em cada área e sete a nove pontos por linha. Nesse estudo foram utilizados 16 isolados do patógeno. Os isolados foram conservados em freezer a $-20^{\circ} \mathrm{C}$ transferindo-se, para crio-tubos contendo sílica gel, grãos de arroz parboilizado esterilizados colonizados pelo patógeno após sete dias de crescimento em meio $\mathrm{BDA}$ a $25^{\circ} \mathrm{C}$. A reativação dos isolados foi efetuada transferindo-se grãos de arroz colonizados pelo fungo para placas de Petri contendo $15 \mathrm{~mL}$ de meio BDA (18,5 g de caldo batata-dextrose, $15 \mathrm{~g}$ de ágar) $\mathrm{L}^{-1}$. Em seguida, procedeu-se o preparo de inóculo para os experimentos.

\section{Preparo de inóculo de $R$. oryzae-sativae.}

Para a produção do inóculo, grãos de arroz parboilizado foram previamente autoclavados a $120^{\circ} \mathrm{C}$ por 30 minutos e então distribuídos em placas de Petri contendo colônias de isolados de $R$. oryzae-sativae em meio BDA, com sete dias de crescimento. Os grãos de arroz foram mantidos nas placas por cinco dias, a temperatura de $25^{\circ} \mathrm{C}$, para que fossem colonizados com micélio fúngico. Após a incubação, os grãos de arroz colonizados pelo fungo foram usados como inóculo. Foram utilizados para inocular os controles grãos de arroz não colonizados pelo fungo, porém mantidos sob as mesmas condições.

Componentes de evolucionabilidade para adaptação de $\boldsymbol{R}$. oryzae-sativae do arroz ao milho.

Para esse estudo foram selecionados oito genótipos diferentes da população BR1 de R. oryzae-sativae e oito genótipos da população BR2, caracterizados previamente por Pereira et al. (20). Foram utilizadas plantas de milho cv. Flintisa, e como controle positivo, ou seja, o hospedeiro suscetível à $R$. oryzae-sativae, utilizou-se plantas de arroz cv. Esmeralda. Os dois hospedeiros foram semeados em copos plásticos contendo vermiculita expandida de textura média, mantidos em casa de vegetação a $25 \pm 2^{\circ} \mathrm{C}$. Cada hospedeiro foi inoculado com os 16 genótipos do patógeno, além da inclusão de um tratamento testemunha com inoculação apenas com grãos de arroz não colonizados pelo fungo. Cada experimento, representado pelos dois hospedeiros distintos, foi delineado de forma inteiramente casualizada, com dez repetições, para controlar o efeito da heterogeneidade ambiental. Os experimentos foram replicados uma vez. A inoculação das plantas de milho e de arroz foi realizada após 24 e 30 dias da semeadura, respectivamente, transferindo um grão de arroz colonizado o qual foi posicionado na base da folha +1 , utilizando-se parafilme para envolver o grão de arroz, dando suporte ao mesmo. Os copos contendo plantas inoculadas foram colocados aleatoriamente em bandejas e embalados dentro de sacos plásticos transparentes mantendo a atmosfera de alta umidade, e incubados a $25 \pm 2^{\circ} \mathrm{C}$, sob $12 \mathrm{~h}$ de luz, até a avaliação. A avaliação dos sintomas da doença foi realizada sete dias após a inoculação dos hospedeiros, fotografando-se uma folha inoculada de cada tratamento, e determinando-se a área foliar doente com o auxílio do software de análise de imagens Assess da APS (Assess: Image Analysis Software for Plant Disease Quantification; L. Lamari, Department of Plant Science, University of Manitoba, Winnipeg, Manitoba, Canadá). Nesta etapa do estudo foram determinados: i) o efeito das duas populações do patógeno sobre a agressividade de $R$. oryzae-sativae do arroz ao milho; ii) os componentes de evolucionabilidade (isto é, uma medida do potencial adaptativo) do fungo para adaptar-se ao milho. A análise de variância (teste $F$ ) foi efetuada usando-se o procedimento estatístico PROC MIXED implementado no programa SAS, analisando-se o efeito de isolados dentro de populações e o efeito de populações.

Para a análise do efeito de populações do patógeno sobre os componentes de evolucionabilidade para a agressividade a cada hospedeiro, a variância explicada pelo fator isolados dentro de cada população foi interpretada como variância genética $\left(V_{G}\right)$ e o erro experimental foi considerado como variância ambiental $\left(V_{E}\right)$. A variância fenotípica foi calculada como $V_{P}=V_{G}+V_{E}$ (28). Os componentes de variância foram determinados por procedimento estatístico implementado no programa R (22), onde utilizou-se os pacotes da distribuição base e o pacote lme4 (2). As variâncias obtidas foram padronizadas pelo quadrado da média da agressividade dos genótipos do patógeno dentro de cada população $\left(m^{2}{ }_{i}, i=1 \ldots n\right.$ genótipos), onde: $V_{G} / m^{2}{ }_{i}=I_{G i} ; V_{E} / m^{2}{ }_{i}=I_{E i}$ e $V_{P} / m^{2}{ }_{i}=I_{p}$, que são os coeficientes de variação para as variâncias genética $\left(I_{G i}\right)$, ambiental $\left(I_{E i}\right)$ e fenotípica $\left(I_{P i}\right)$, sendo então consideradas medidas de evolucionabilidade ou de resposta à seleção (14). A herdabilidade para o caráter agressividade do patógeno foi calculada como a razão entre a variância genotípica $\left(I_{G}\right)$ e a variância fenotípica $\left(I_{P}\right)$, ambas padronizadas $\left(I_{P}=I_{G}+I_{E}\right)$. O intervalo de confiança a $95 \%$ para as estimativas dos componentes de variância e da herdabilidade foi calculado por meio de re-amostragens por bootstrap ordinário ou não-paramétrico $(6 ; 8)$. O bootstrap foi implementado no ambiente R (22), usando-se os pacotes da distribuição 
base e o pacote lme4 (2). Porque tanto as estimativas de $h^{2}$ e de $I_{G}$ predizem a resposta à seleção $R\left(R=h^{2} i r_{P}\right.$, onde $i=$ intensidade de seleção e $r_{P}=$ desvio padrão fenotípico do atributo antes da seleção, de acordo com Falconer e Mackay (10); ou $R=I_{G} X$, onde $X=$ intensidade de seleção, de acordo com Houle (14), ambos podem ser consideradas medidas de evolucionabilidade ou do potencial adaptativo de uma população $(14 ; 20 ; 21 ; 29)$.

Determinação do índice de diferenciação entre as populações BRA1 e BRA2 por caracteres quantitativos $\left(Q_{S T}\right)$.

O nível de diferenciação populacional em caracteres quantitativos (i.e $Q_{S T}$, que é análogo ao $F_{S T}$ ) foi estimado com base em componentes de variância genética "entre" e "dentro de" populações, como descrito por Zhan e colaboradores (32) em estudo conduzido com a espécie haploide de fungo fitopatogênico Mycosphaerella graminicola. Para espécies diploides (ou organismos dicarióticos como $R$. oryzae-sativae, i.e. contendo dois núcleos independentes em cada célula), o nível de diferenciação populacional em caracteres quantitativos é expresso por:

$$
Q_{S T=} \delta_{A P}^{2} /\left(\delta_{A P}^{2}+2 \delta^{2}{ }_{W P}\right)
$$

onde $\delta_{A P}^{2}$ é a variância genética entre populações em cada condição estudada e $\delta_{W P}^{2}$ é a variância genética dentro de populações. Os valores de $Q_{S T}$ e o intervalo de confiança de $95 \%$ para as estimativas de $Q_{S T}$ foram calculados por meio de análise de bootstrap implementado no ambiente R (22). Já os valores de $F_{S T}$ foram determinados com base nos dados de frequências alélicas de cinco marcadores microssatélites obtidos por Pereira et al. (20) e de acordo com o método estatístico genético empregado pelos mesmos autores. Comparou-se os padrões de variação genética por marcadores microssatélites $\left(F_{S T}\right)(20)$, com a variação em caracteres quantitativos $\left(Q_{S T}\right)$ para inferir sobre a importância do efeito do processo de seleção natural atuando sobre as populações BRA1 e BRA2 de R. oryzae-sativae de arroz utilizadas neste estudo.

\section{RESULTADOS E DISCUSSÃO}

Detectou-se diferenças significativas de agressividade entre isolados dentro de populações do patógeno tanto em milho cv. Flintisa quanto em arroz cv. Esmeralda. Entretanto, não houve diferença entre as populações BRA1 e BRA2 para os dois hospedeiros analisados (Tabela 1, Figuras 1 e 2).

A análise combinada das duas réplicas indicou diferença entre réplicas $\left[F_{\text {réplicas }}=5,01\right.$ para o experimento de milho $(p=0,026) \mathrm{e}$ $F_{\text {réplicas }}=27,30(p 0,001)$ para o experimento de arroz]. Por sua vez, a interação réplica vs. população foi não significativa $\left[F_{\text {réplicas* populacãao }}=\right.$ 1,28 para o experimento de milho $(p=0,259)$ e $F_{\text {réplicas }}$ população $=0,64(p$ $=0,436)$ para o experimento de arroz], indicando que os experimentos foram completamente reproduzíveis.

Em milho e em arroz, a análise conjunta de dois experimentos indicou diferenças significativas entre a média de agressividade da réplica 1 e da réplica $2(p \leq 0,05)$. A agressividade média das populações BRA1 e BRA2 de R. oryzae-sativae em milho variou do máximo de 5,7 ao mínimo de 2,6\% ( \pm 0.95$)$ de área foliar infectada na réplica 1 , e de 6,8 a 5,9\% $( \pm 0.92)$ na réplica 2 do experimento. Em arroz, a agressividade média das populações de isolados do patógeno variou de $4,7 \%$ a 3,6\% $( \pm 0.58)$ de área foliar infectada na réplica 1 , e de 7,56 a 7,54\% $( \pm 0.68)$ na réplica 2 do experimento. (Figura 1). Mesmo em ambiente de casade-vegetação, é provável que as condições de condução da réplica 1 dos experimentos (durante a primavera de 2015) foram relativamente menos conducentes à doença que as da réplica 2 (durante o verão). Entretanto, o efeito da interação réplica*população foi não significativo, indicando completa reprodutibilidade das observações nas duas populações, independente do experimento (Tabela 1).

Avaliou-se, então, a adaptabilidade patogênica das duas populações amostradas de $R$. oryzae-sativae ao milho. A adaptabilidade foi estimada por meio de medidas de evolucionabilidade ou de resposta à seleção [i.e., coeficiente de variação das variâncias genética $\left(I_{G}\right)$ e ambiental $\left(I_{E}\right)$ e herdabilidade de senso amplo $\left(h^{2}\right)$ para o atributo agressividade]. Variação genética para adaptação patogênica ou ambiental pode resultar em adaptação permanente do organismo a um hospedeiro ou ambiente distinto $(5 ; 7 ; 10 ; 11)$.

No geral, as variâncias ambientais padronizadas $\left(I_{E}\right)$ foram superiores às variâncias genotípicas padronizadas $\left(I_{G}\right)$ para a agressividade de $R$. oryzae-sativae ao milho e ao arroz (Figura 3). Assim, os valores de herdabilidade no sentido amplo para agressividade ao milho foram inferiores a 0,45 (Figura 3), considerados de medianos a baixos (5). Enquanto a população BRA1 do patógeno,

Tabela 1. Modelo linear misto, os efeitos de população e isolado (dentro de uma população) na agressividade de Rhizoctonia oryzae-sativae em milho e arroz.

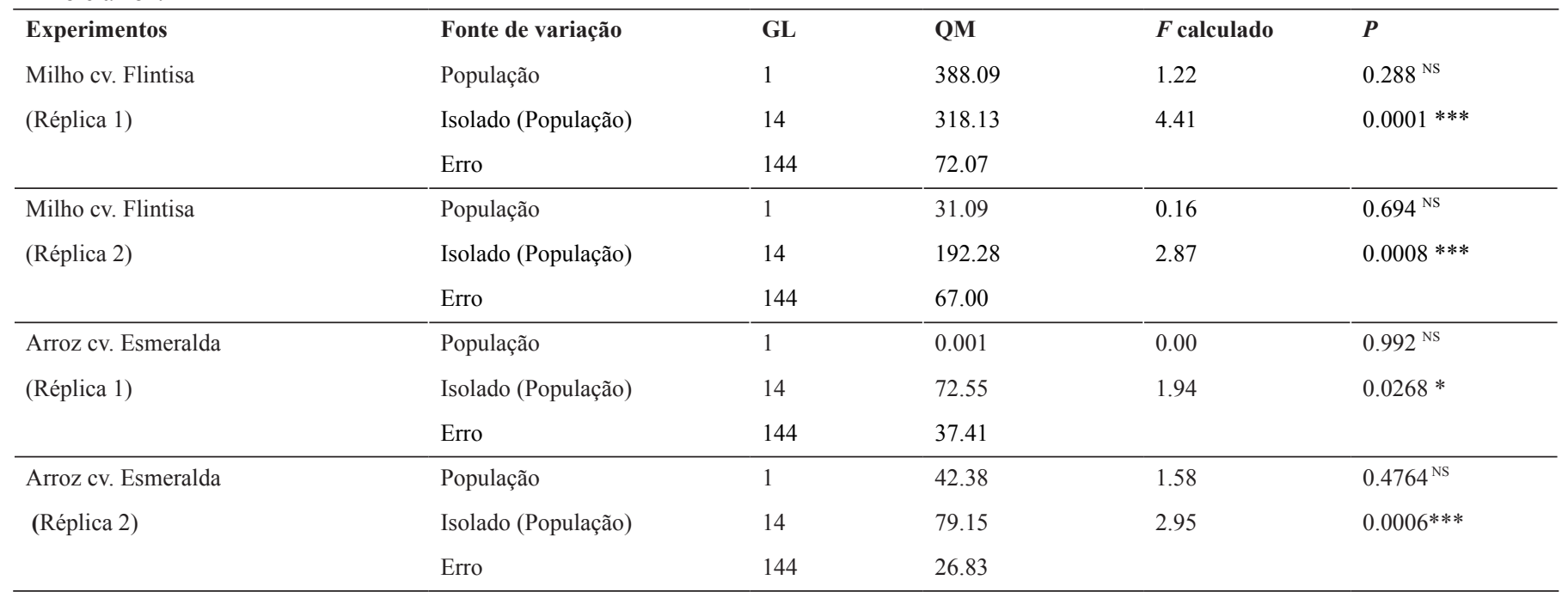

***Significativo pelo teste $F$ a $p 0.001 ; * p 0,05$. 


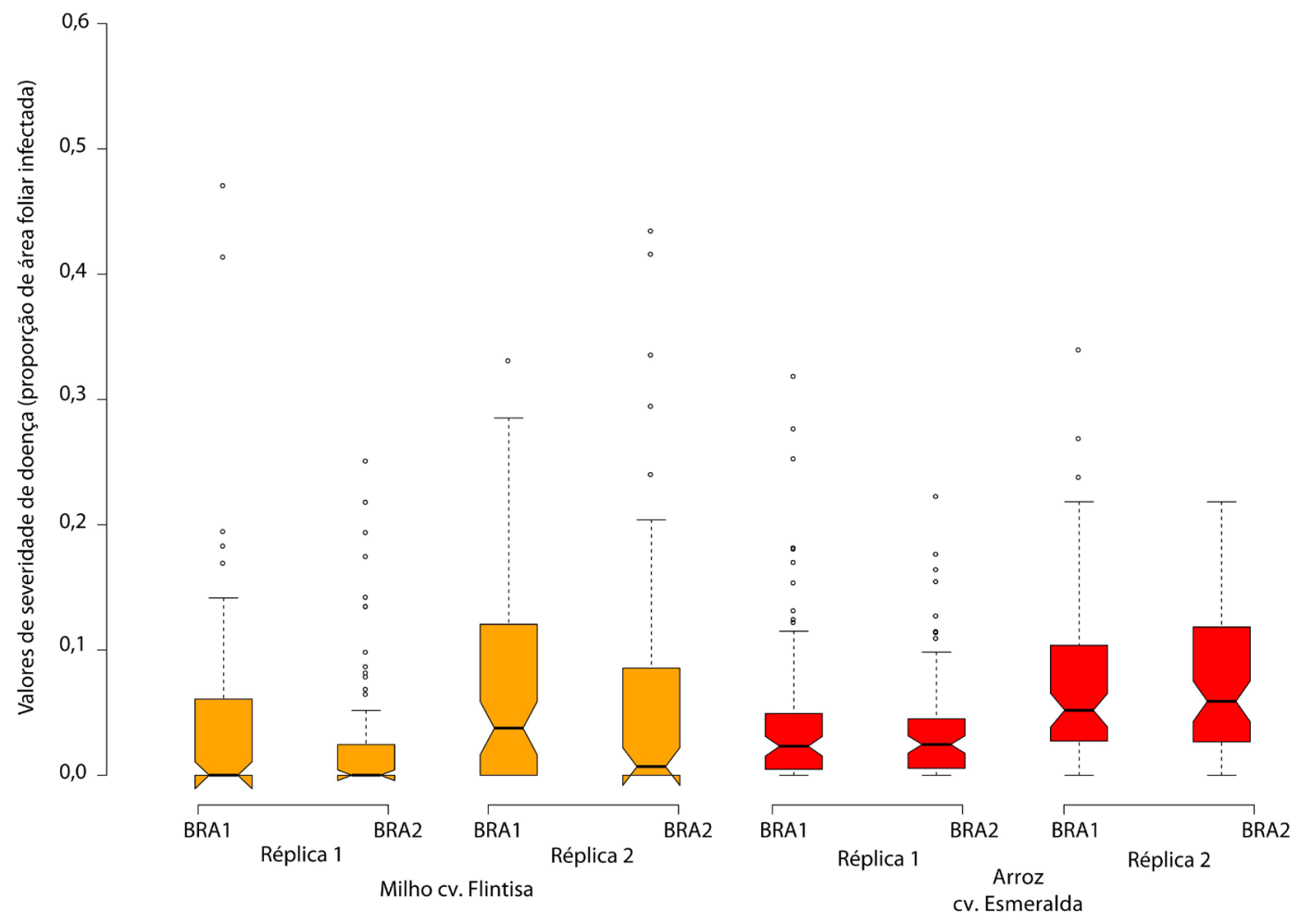

Figura 1. Agressividade das populações BRA1 e BRA2 de Rhizoctonia oryzae-sativae ao milho e arroz*.

* O valor da mediana de cada box-plot representa a medida da agressividade do conjunto de 8 isolados e 10 repetições. O entalhe marca o intervalo de confiança de $95 \%$ para as medianas. Se os entalhes de dois diagramas não se sobrepõem, podemos assumir (nível de significância de 0,05) que as medianas são diferentes.

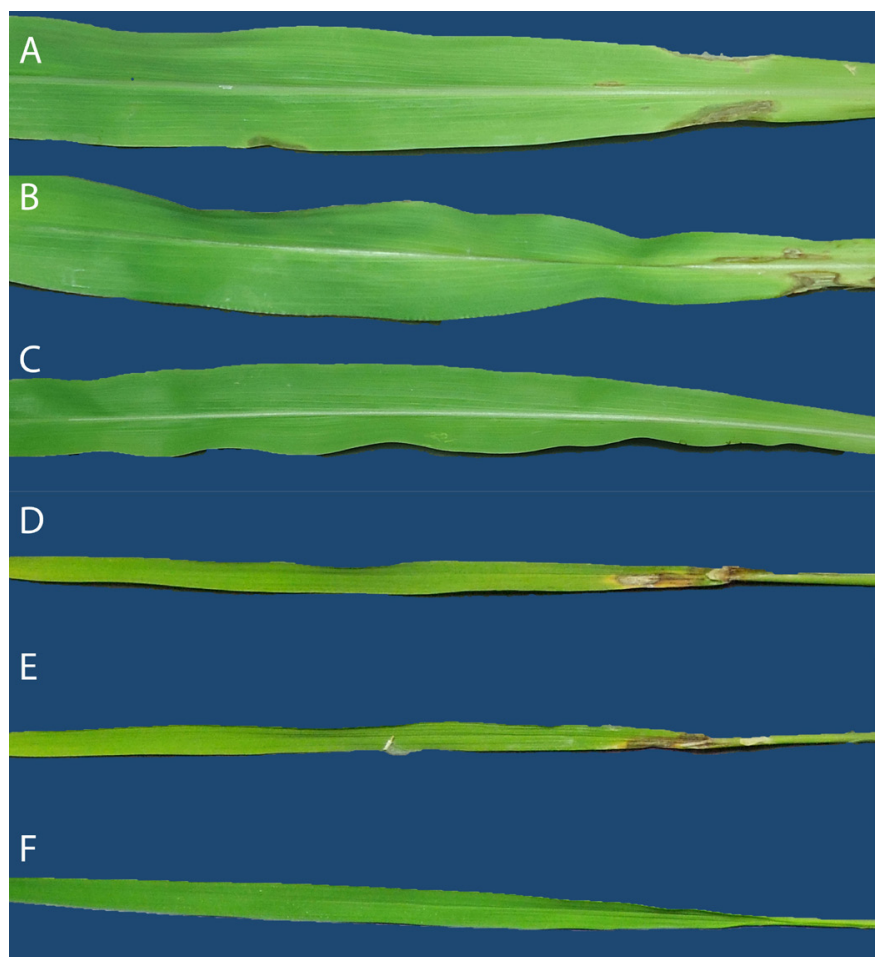

Figura 2. Sintomas causados por Rhizoctonia oryzae-sativae em milho cv. Flintisa da população BRA1 (A) e população BRA2 (B) e sintomas em arroz cv. Esmeralda da população BRA1 (D) e população BRA2 (E). Folhas não inoculadas e sem sintomas se referem aos controles (C) e (F) de milho e arroz, respectivamente. quando inoculada em milho, apresentou mediana de herdabilidade de 0,36 com desvio padrão de $\pm 0,10$, a população BRA2 apresentou valor de mediana de herdabilidade significativamente menor $(0,14$ $\pm 0,08$ ) nos dois experimentos (Figura 3 ). Por sua vez, em arroz a herdabilidade para agressividade da população BRA1 $(0,18 \pm 0,09)$ não foi significativamente diferente à da população BRA2 $(0,21 \pm 0,09)$, nos dois experimentos (Figura 3). Dessa forma, a gama de fenótipos ou variação na agressividade dos isolados de $R$. oryzae-sativae das duas populações testadas tanto em milho quanto em arroz refletiu, basicamente, o efeito da variância ambiental interferindo de forma distinta na expressão gênica de genótipos do patógeno $(7 ; 31)$.

Em estudo realizado por Pereira et al. (20), utilizando genótipos de R. oryzae-sativae provenientes da mesma região, também observou-se que os valores da variância ambiental foram superiores aos valores da variância genética em dois cultivares de Urochloa spp. (capim braquiária), resultando em valores baixos de $h^{2}$ para agressividade (28), como detectado para milho em nosso estudo. Entretanto, em Urochloa ruziziensis detectou-se maior herdabilidade da resposta fenotípica (i.e., maior variância genética para agressividade), indicando mais alta evolucionabilidade para agressividade (28), o que constituiria um passo importante para mudanças evolutivas nas populações do patógeno (27).

Quanto à natureza predominante da pressão de seleção nas populações avaliadas de $R$. oryzae-sativae, os valores de $F_{S T}$ foram comparados aos valores obtidos de $Q_{S T}$. A divergência genética entre as populações BRA1 e BRA2 medida pelo índice geral de fixação $F_{S T}$ foi de - 0,055 ( $p=0,964)$, portanto, não se detectou diferenciação genética entre o par de populações BRA1 e BRA2, uma vez que o valor de $F_{S T}$ não foi estatisticamente diferente de zero. As populações do patógeno também não divergiram fenotipicamente nos dois hospedeiros $\left(Q_{S T}\right.$ não 
A. Nitrocr.fintica - Péplica 1

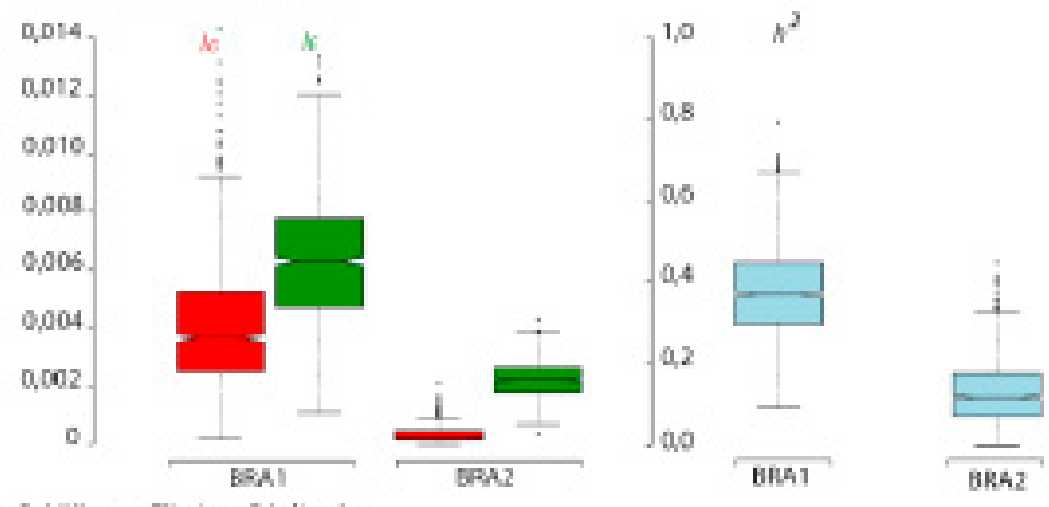

Q. Milho \&v. Flintise - Rieplica 2

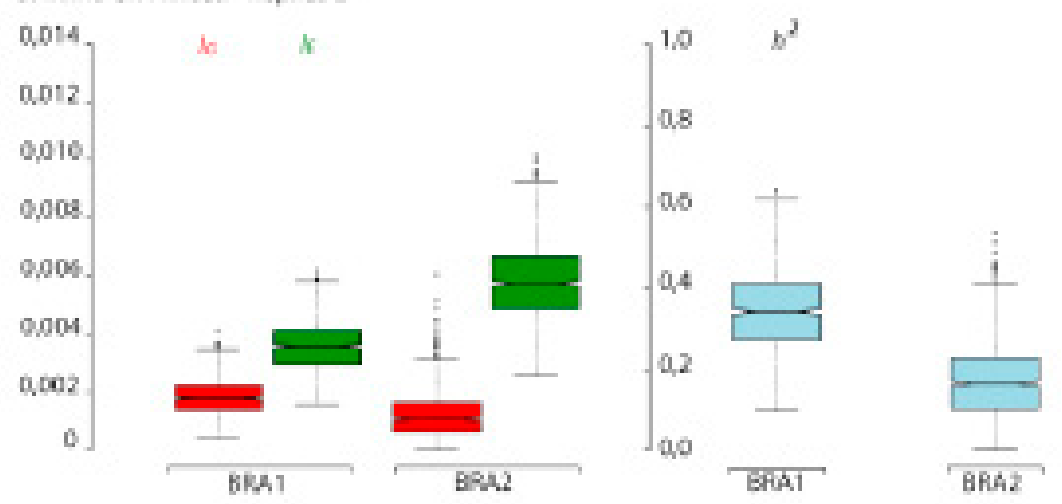

C. Amozer. Ecroralda - Alplica 1
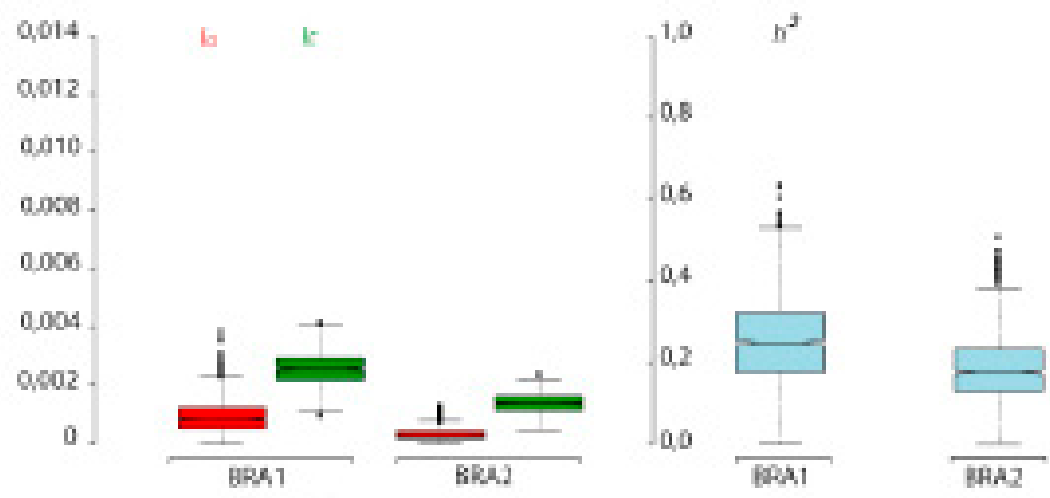

D. Aruca cv. Esmeraida = Reeplica 2
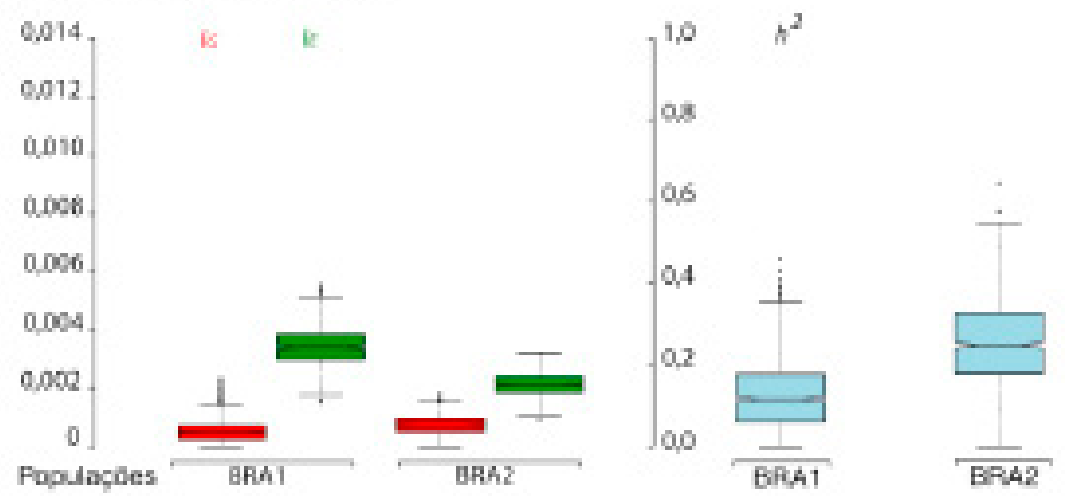

Figura 3. Componentes de evolucionabilidade $\left(I_{G}=\right.$ variância genética, $I_{E}=$ variância ambiental, ambas padronizadas $)$ e herdabilidade $h^{2}$ para agressividade ao milho e ao arroz, como resposta à infecção por duas populações de Rhizoctonia oryzae-sativae obtidas de arroz no Vale do Paraíba, SP. *

*Os diagramas de caixas (boxplots) contém a linha da mediana aproximadamente em seu centro e $50 \%$ dos dados (entre os quartís 25 e $75 \%$ ) gerados por bootstrap considerando 999 re-amostragem. As barras verticais indicam os valores máximos e mínimos observados e os círculos os valores atípicos. O entalhe marca o intervalo de confiança de $95 \%$ para as medianas. 


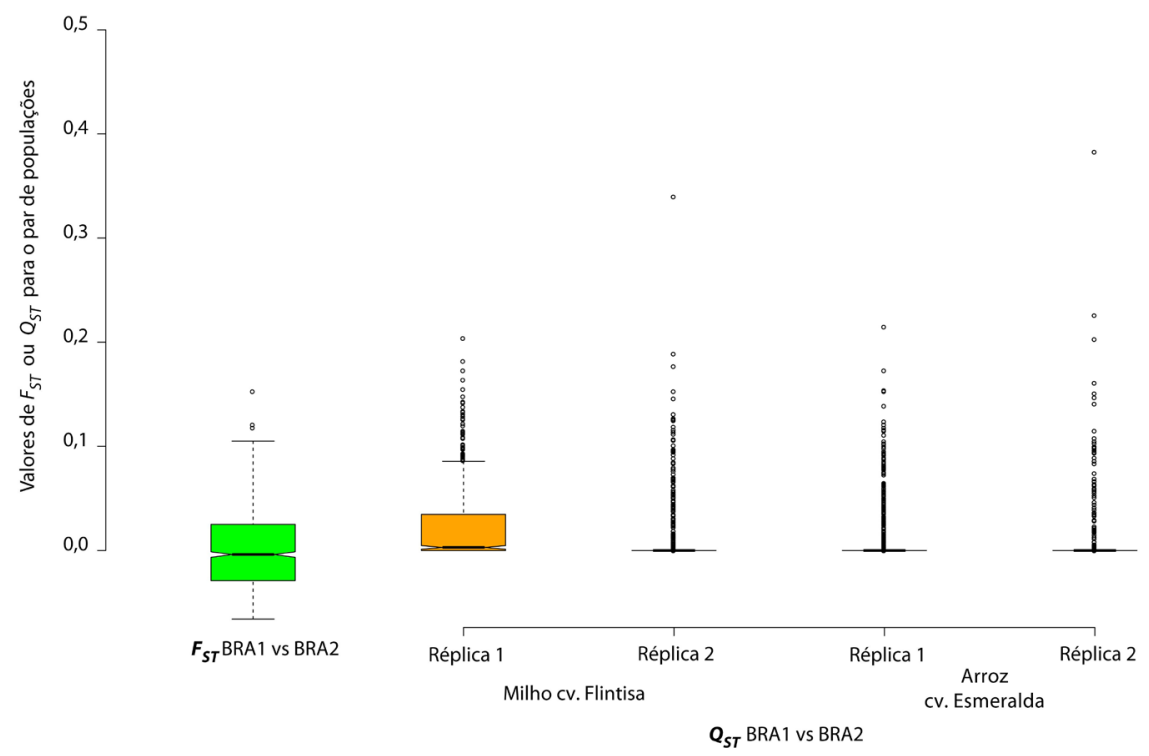

Figura 4. Comparação entre valores de $F_{S T}$ e de $Q_{S T}$ da divergência entre populações BRA1 e BRA2 para agressividade de Rhizoctonia oryzaesativae ao milho e ao arroz.

** Os diagramas de caixas (boxplots) contém a linha da mediana aproximadamente em seu centro e 50\% dos dados (entre os quartís 25 e $75 \%$ ) gerados por bootstrap considerando 999 re-amostragem. As barras verticais indicam os valores máximos e mínimos observados e os círculos os valores atípicos. O entalhe marca o intervalo de confiança de $95 \%$ para as medianas.

significativamente diferentes de zero). Nenhuma diferença significativa foi encontrada entre os valores de $F_{S T}$ e $Q_{S T}$ para o par de populações de isolados de $R$. oryzae-sativae inoculados em milho cv. Flintisa e em arroz cv. Esmeralda, tendendo assim, à divergência sob neutralidade (18) (Figura 4).

Sob neutralidade, espera-se uma concordância entre a diferenciação genética para caracteres fenotípicos, $Q_{S T}$, e medidas de diversidade genética neutra, $F_{S T}(16 ; 24)$. Nessa situação, de acordo com JaramilloCorrea et al. (15), o acúmulo de mutações neutras (afetando igualmente o genoma inteiro do organismo) seguido de deriva genética, é, possivelmente, o responsável pela adaptação regional entre populações. Por sua vez, estimativas de $Q_{S T}$ são intrinsicamente enviesadas e sua precisão para os conjuntos de dados analisados é considerada baixa quando o número de pares de populações e/ou de atributos fenotípicos analisados é baixo (18). Dessa forma, os resultados obtidos no presente estudo devem ser interpretados dentro de certos limites, considerando o número reduzido de populações do patógeno que se analisou e também por restringirmos o estudo a uma única variedade de milho. Dentro desses limites, concluiu-se que as duas populações de $R$. oryzae-sativae analisadas nesse estudo apresentaram patogenicidade e variação na agressividade ao milho, com predominância de baixa herdabilidade para este atributo. A divergência entre as duas populações do patógeno se deveu, possivelmente, à efeito de seleção com tendência à neutralidade. Muito embora a doença ainda não tenha sido relatada em milho, sob condições de campo, é provável que as duas populações de $R$. oryzaesativae do arroz já estivessem adaptadas ao milho, visto que os níveis de agressividade assemelharam-se aos observados para o arroz.

\section{AGRADECIMENTOS}

A primeira autora agradece à Coordenação de Aperfeiçoamento de Pessoal de Nível Superior-CAPES pela concessão de bolsa de estudo de mestrado. Este trabalho foi financiado por auxílio à pesquisa concedido pela FAPESP (Fundação de Amparo à Pesquisa do Estado de São Paulo, Brasil) a P.C. Ceresini (FAPESP - Biota 2011/501503), por bolsas de pesquisa Pq-2 (307361/2012-8 e 307295/2015-0) e auxílio (485244/2012-8) concedidos pelo CNPq (Conselho Nacional de Desenvolvimento Científico e Tecnológico) a P. C. Ceresini. V. L. Castroagudín recebeu bolsa PDJ do CNPq (504073/2011-7, de 2012 a 2014) e FAPESP / CAPES (2014/25904-2, de 2015 a 2016). D. A. S. Pereira recebeu bolsa de mestrado da FAPESP (2013/11944-0). A. F. Dorigan foi bolsista PIBIC CNPq/UNESP (de 08/2016 a 02/2017).

\section{REFERÊNCIAS}

1. Amaral, R. E. M.; Issa, E.; Souza, D. M.; Malavolta, V. M. A.; Leite, L. C.; Jesus, L. M. Estudos sobre a queima das bainhas do arroz Oryza sativa L. Arquivos do Instituto Biológico, São Paulo, v. 46, p. 55-62, 1979.

2. Bates, D.; Maechler, M. lme4: Linear mixed-effects models using S4 classes. R package version 0.999375-34. 2010. Disponível em: <http:/ CRAN.R-project.org/package=lme4> . Acessado em 12/12/2015.

3. Bernardes De Assis, J.; Peyer, P.; Rush, M. C.; Zala, M.; Mcdonald, B. A.; Ceresini, P. C. Divergence between sympatric rice- and soybean-infecting populations of Rhizoctonia solani anastomosis group-1 IA. Phytopathology, St. Paul, v. 98, n. 12, p. 1326-1333, 2008.

4. Bettiol, W.; Ghini, R. Proteção de plantas em sistemas agrícolas alternativos. In: Michereff, S. J.; Barros, R. (Ed.). Proteção de plantas na agricultura sustentável. Recife: UFRPE, 2001. p.1-14.

5. Cruz, C. D. Princípios da genética quantitativa. Viçosa: Universidade Federal de Viçosa, 2005. 394 p.

6. Davison, A. C.; Hinkley, D. V. Bootstrap methods and their application. New York: Cambridge University Press, 1997. 582 p.

7. Dybdahl, M. F.; Kane, S. L. Adaptation vs. phenotypic plasticity in the success of a clonal invader. Ecology, Washington, v. 86, n. 6, p. 1592-1601, 2005.

8. Efron, B.; Tibshirani, R. An introduction to the bootstrap. New York: Chapman \& Hall, 1993. $456 \mathrm{p}$.

9. Eskinazi, B. G.; Souza, J. G. Especialização produtiva e homogeneização territorial: A monocultura de eucalipto no Vale do Paraíba Paulista e as transformações nas dinâmicas de produção. Revista Pegada, Presidente Prudente, v. 14, n. 2, p. 18, 2013.

10. Falconer, D. S.; Mackay, T. F. C. Introduction to quantitative genetics. 4 ed. Harlow, Essex, UK: Longmans Green, 1996. 464 p. 
11. Fangue, N. A.; Hofmeister, M.; Schulte, P. M. Intraspecific variation in thermal tolerance and heat shock protein gene expression in common killifish, Fundulus heteroclitus. Journal of Experimental Biology, London, v. 209, p. 2859-2872, 2006.

12. Gollo, E. A.; Robaina, A. D.; Marchesan, E.; Donato, G.; Silva, M. F.; Silva, A. L. Resposta do milho à irrigação em áreas de arroz. In: Congresso brasileiro de arroz irrigado, 2015, Pelotas, RS. Anais. Pelotas: Sociedade Sul-Brasileira de Arroz Irrigado, 2015. p.4.

13. González-Vera, A. D.; Bernardes-De-Assis, J.; Zala, M.; Mcdonald, B. A.; Correa-Victoria, F.; Graterol-Matute, E. J.; Ceresini, P. C. Divergence between sympatric rice- and maize-infecting populations of Rhizoctonia solani AG 1 IA from Latin America. Phytopathology, St. Paul, v. 100, n. 2, p. 172-182, 2010.

14. Houle, D. Comparing evolvability and variability of quantitative traits. Genetics, Austin, v. 130, n. 1, p. 195-204, 1992.

15. Jaramillo-Correa, J. P.; Beaulieu, J.; Bousquet, J. Contrasting evolutionary forces driving population structure at expressed sequence tag polymorphisms, allozymes and quantitative traits in White spruce. Molecular Ecology, Oxford, v. 10, n. 11, p. 2729-2740, 2001.

16. Lande, R. Neutral theory of quantitative genetic variance in an island model with local extinction and colonization. Evolution, Lancaster, v. 46, n. 2, p. 381-389, 1992.

17. Lanoiselet, V. M.; Cother, E. J.; Ash, G. J. Aggregate sheath spot and sheath spot of rice. Crop Protection, Guildford, v. 26, n. 6, p. 799-808, 2007.

18. Merila, J.; Crnokrak, P. Comparison of genetic differentiation at marker loci and quantitative traits. Journal of Evolutionary Biology, Oxford, v. 14 , n. 6, p. 892-903, 2001.

19. Nunes, C. D.; Ribeiro, A. S.; Terres, A. L. Principais doenças do arroz irrigado e seu controle. In: Gomes, A. S.; Magalhães Júnior, A. M. (Ed.). Arroz irrigado no sul do Brasil. Brasília, DF: Embrapa Informação Tecnológica, 2004. p.579-633

20. Pereira, D. A. S.; Ceresini, P. C.; Castroagudín, V. L.; Ramos-Molina, L. M.; Chavarro-Mesa, E.; Negrisoli, M. M.; Campos, S. N.; Pegolo, M. E. S.; Takada, H. M. Population genetic structure of Rhizoctonia oryzae-sativae from rice in Latin America and its adaptive potential to emerge as a pathogen on Urochloa pastures. Phytopathology, St. Paul, v. 107, n. 1, p. 121-131, 2016

21. Poloni, N. M.; Molina, L. M. R.; Mesa, E. C.; Garcia, I. L.; Ceresini, P.
C. Evidência de que o fungo Rhizoctonia solani AG-1 IA adaptado à Urochloa na Colômbia mantém ampla gama de hospedeiros incluindo o milho. Summa Phytopathologica, Botucatu, v. 42, p. 228-232, 2016.

22. R Development Core Team. R: A language and environment for statistical computing. Vienna, Austria: R Foundation for Statistical Computing, 2008. $2673 \mathrm{p}$.

23. Reis, E. M.; Casa, R. T.; Bianchin, V. Controle de doenças de plantas pela rotação de culturas. Summa Phytopathologica, Botucatu, v. 37, p. 85-91, 2011

24. Spitze, K. Population structure in Daphnia obtusa: quantitative genetic and allozymic variation. Genetics, Austin, v. 135, n. 2, p. 367-74, 1993.

25. Stone, L. F.; Guimarães, C. M. Influência de sistemas de rotação de culturas nos atributos físicos do solo. Santo Antônio de Goiás: Embrapa., p. 15 p., 2005.

26. Stukenbrock, E. H.; Mcdonald, B. A. The origins of plant pathogens in agro-ecosystems. Annual Review of Phytopathology, Palo Alto, v. 46, n. 1, p. 75-100, 2008.

27. West-Eberhard, M. J. Developmental plasticity and evolution. New York: Oxford University Press, 2003. 916 p.

28. Willi, Y.; Frank, A.; Heinzelmann, R.; Kälin, A.; Spalinger, L.; Ceresini, P. C. The adaptive potential of a plant pathogenic fungus, Rhizoctonia solani AG-3, under heat and fungicide stress. Genetica, v. 139, n. 7, p. 903-908, 2011.

29. Willi, Y.; Van Buskirk, J.; Hoffmann, A. A. Limits to the adaptive potential of small populations. Annual Review of Ecology Evolution and Systematics, Palo Alto, v. 37, p. 433-458, 2006.

30. Willocquet, L.; Fernandez, L.; Savary, S. Effect of various crop establishment methods practised by Asian farmers on epidemics of rice sheath blight caused by Rhizoctonia solani. Plant Pathology, Oxford, v. 49, n. 3, p. $346-354,2000$.

31. Winkler, W. C.; Breaker, R. R. Regulation of bacterial gene expression by riboswitches. Annual Review of Microbiology, Palo Alto, v. 59, p. 487517, 2005.

32. Zhan, J.; Linde, C. C.; Jürgens, T.; Merz, U.; Steinebrunner, F.; Mcdonald, B. A. Variation for neutral markers is correlated with variation for quantitative traits in the plant pathogenic fungus Mycosphaerella graminicola. Molecular Ecology, Oxford, v. 14, n. 9, p. 2683-2693, 2005. 